\title{
HETEROCYCLES AWARD
}

\section{HETEROCYCLES is pleased to announce Heterocycles Award. In recognition of an outstanding oral presentation at the $48^{\text {th }}$ Congress of Heterocyclic Chemistry September 3 to 5, 2018, Nagasaki Brick Hall, Nagasaki, Japan}

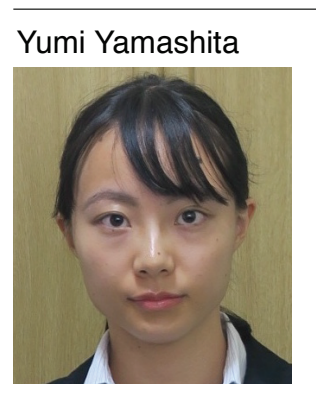

Akira Matsumoto

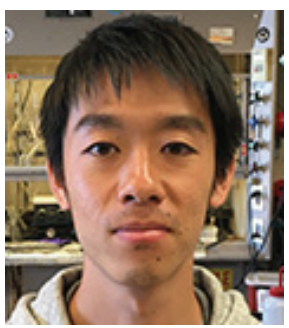

Shobu Hiraoka

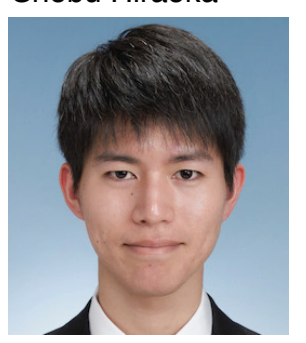

Title: Development and Application of a Novel Indole Synthesis by Ring Expansion Reaction of Oxime Sulfonate

Yumi Yamashita was born in 1996 in Sendai, Japan. She is a first year Master course student in the Graduate School of Pharmaceutical Sciences, Tohoku University, working with Prof. Hidetoshi Tokuyama. Her research interests include development of novel indole synthesis and its application to synthesis of natural products.

Title: Organocatalytic Cycloetherification for Asymmetric Cyanation of Acylsilanes

Akira Matsumoto was born in 1990 in Gifu, Japan. He is a Ph.D. student in Department of Material Chemistry, Graduate School of Engineering, Kyoto University, Japan (2016 - present) working with Prof. Seijiro Matsubara. His research interest includes the development of novel methods for asymmetric synthesis of pharmaceutically important chiral carbinols via organocatalytic heterocycle formation.

Awards: (1) CSJ Poster Presentation Award at the 4th CSJ Chemistry Festa 2014, Tokyo, Japan. (2) Poster Presentation Award at the 36th Synthetic Organic Seminar, Kyoto, Japan.

Title: Enantioselective Total Synthesis of Cylindricine C by Nucleophilic Approach to Nitrones from $\mathrm{N}$-Hydroxyamides

Shobu Hiraoka was born in 1993 in Hyogo, Japan. He is a second year Master course student in Graduate School of Science and Technology, Keio University working with Prof. Noritaka Chida and Prof. Takaaki Sato. His research interest includes development of the nucleophilic approach to nitrones and the application to natural products syntheses. 